\title{
Designing and validation: a questionnaire of hope for family members of patients hospitalized in intensive care unit
}

\author{
Foad Rahimi $^{1}$, Fatemeh Oskouie ${ }^{2}$, Abbas Ebadi $^{3}$
}

${ }^{1}$ Ph.D. Student in Nursing, School of Nursing and Midwifery, International Campus, Iran University of Medical Sciences, Tehran, Iran

${ }^{2}$ Nursing Care Research Center and School of Nursing and Midwifery, Iran University of Medical Sciences, Tehran, Iran

${ }^{3}$ Ph.D. of Nursing, Assistant Professor, Department of Nursing, Faculty of Nursing and Midwifery, Baqiyatallah University Medical Sciences, Tehran, Iran

\section{Type of article: Original}

\begin{abstract}
Background: Families of patients are faced with stressors in the intensive care unit (ICU) that cannot be controlled sometimes. Having hope is one of the strategies for obtaining self-control in patients' families, which deals with such situations.

Objective: The purpose of this study was to design and validate a questionnaire of hope for family members of patients hospitalized in intensive care units.

Methods: This study was conducted for family members of patients hospitalized in the intensive care units of Kurdistan and Tehran provinces, in Iran, between the years 2015-2016. In this study, 126 family members were selected using convenience sampling. The study was conducted using a questionnaire of hope scale for family members of patients hospitalized in intensive care units and demographic characteristics. During the study, construct and criterion validity of the tool was determined. The Reliability was determined using internal consistency and test-retest coefficient. Data were analyzed through factor analysis, correlation coefficient and Cronbach's alpha. Construct validity of the scale was analyzed using exploratory factor analysis (EFA).

Results: Participants in this study included 12 family members of patients hospitalized in the intensive care units. Cronbach's alpha coefficients obtained from analysis of questionnaires completed by family members of patients was 0.916. Cronbach's alpha under the first scale (compatibility) was 0.898 , Cronbach's alpha of the second subscale (self-confidence) was $87 \%$, Cronbach's alpha under the third subscale (Sense of responsibility) was 0.770. The fourth subscale (Looking to the future) was 0.571. Pearson correlation coefficients between the scores obtained from two family members responses to the hope scale were 0.939 which showed that scale stability was average. As a result, exploratory factor analysis, four factors were found that were named according to the statements of each group.

Conclusion: Consistency coefficients between the two tests was 0.939 that the stability over time the questionnaire was confirmed. A questionnaire of hope in the intensive care unit can measure different dimensions of hope to the families of these patients and help to improve the care of these patients. Validity and reliability of "scale for hope of families of these patients" was appropriate and it could be used to measure hope in families of these patients.

Keywords: Psychometric scale, Validity, Reliability, Hope scale
\end{abstract}

\section{Introduction}

Hospitalization in the intensive care unit (ICU) has a potentially unfavorable concept for patients and their families, and can pose a lot of problems for them, of which it is inevitable to escape from their negative effects (1). According

\section{Corresponding author:}

Foad Rahimi, School of Nursing and Midwifery (International Campus), Iran University of Medical Sciences, Tehran, Iran. Tel: +98.8733239908, Email: Foadrahimi63@yahoo.com

Received: January 20, 2017, Accepted: June 14, 2017, Published: October 2017

iThenticate screening: June 05, 2017, English editing: September 20, 2017, Quality control: October 12, 2017

(C) 2017 The Authors. This is an open access article under the terms of the Creative Commons Attribution-NonCommercialNoDerivs License, which permits use and distribution in any medium, provided the original work is properly cited, the use is non-commercial and no modifications or adaptations are made. 
to statistics, annually, 2000 new cases of hospitalized patients in intensive care units are reported in Iran and 500 related deaths in intensive care units are reported in Iran every year. Fear of losing a family member, fear for the future, fear of disease financial burden on the family, changes in family roles, anxiety, depression, loneliness, and hopelessness are considered as the threats that can affect the integrated family (2). Family members use coping strategies such as hope and spirituality to cope with their stress which is associated with their psychosocial development (3). Some researchers believe that concept of hope is associated with that of matching concepts, faith and other means; thus, accepting the existing conditions can be considered as an effective response to stressors (4). Hope enhances physiological and psychological performance, and its absence leads to the premature failure in people's function (5-8). Based on the literature and research related to nursing, hope is an early stage of adaptation and coping strategies (9). Hoping to have a better life leads to improvement in the individuals' compatibility (10). Other studies indicate that we should expect to maintain health and achieve necessary goals (11). Hope can have a healing effect on health outcomes, so one of the nurses' roles is to strengthen the client's expectation. Nurses are able to raise people's hope in a positive manner and by doing so, improve their health outcomes (12). In Iran, despite the importance of community health concepts such as hope, little research has been conducted in this regard. One reason may be the lack of appropriate tools to measure this concept. Little progress in social sciences and behavioral sciences are due to difficulties associated with the structure of scales (13). During the past decade, psychometric properties were tested in nursing to design tools that are used for measuring various phenomena in the realm of nursing. To ensure validity and reliability of the obtained results, degree of precision of scales is important $(14,15)$. Data collection is one of the most important stages of research which requires the use of appropriate tools. To collect data, researchers should design their original questionnaire or use external valid and reliable questionnaires (16). One of the tools that had its reliability and validity evaluated and approved to measure hope in teens is "Hopefulness Scale for Adolescents (HAS) (17). Hopefulness Scale for Adolescents in Iran was translated by Rassouli, and its psychometric properties were examined in adolescents living in boarding centers $(18,19)$. Since psychometric properties of " hope scale for family members with a patient hospitalized in ICU" were examined only in certain groups of family members, in order to implement the objective of research groups and research units that make up family members' population, examining validity and reliability are essential. In other words, it is important to study the concept of hope and its role in sustaining and improving family health. From the other side, unavailability of a suitable scale to measure this concept in family members of patient hospitalized in ICU requires us to examine validity and reliability of an appropriate scale. Designing a reliable and valid scale prepares the ground for future applied studies. Therefore, the aim of this study was to examine the Designing and Validation questionnaire of hope for family members of patients hospitalized in intensive care units between the years 2015-2016.

\section{Material and Methods}

This was a methodological study to design and determine the psychometric properties of hope scale of family members of patients hospitalized in the intensive care unit. A 2006 study by LoBiondo and Haber showed that methodological study is regulated through theoretical and applied aspects of mathematics, statistics, measurement, and other sciences that are associated with collection and analysis of data (14). In this study, statements of family members about their hopes, were collected and analyzed using a content analysis research. This was the result of a semi-structured interview with 12 family members living in a special care unit who were willing to participate in the study. At first, the word hope was defined based on the lived experience of the above-mentioned family members. Then the interviews were continued until data saturation. The quantitative part of the study was conducted by family-members of patients in intensive care units of Kurdistan and Tehran provinces in Iran in 2015-2016. We used convenience sampling in our study and selected 126 family members. The instruments used in this study consisted of a questionnaire on demographic characteristics, hope scale of family members of patients admitted to the intensive care unit, and beck depression scale. Hope scale of premature mothers in this study was developed after several stages, ending up with 39 items. For the evaluation of psychometric properties, we used hope scale construct validity using factor analysis method. Sampling adequacy test was evaluated using Kaiser-Mayer-Okin (KMO) which was 0.673 . KMO value varies between zero and one. Higher values indicate better factor analysis. Values higher than $0.90,0.80$, and 0.60 are rated as excellent, good and fair respectively. Factor analysis was justified to determine whether the correlation matrix obtained was significantly different from zero. In other words, we wanted to specify if there was enough correlation between interpolate tools that could be integrated. Therefore, Bartlett's test was used resulting in a value of $5282.934(\mathrm{p}=0.000)$. For hope scale divergent validity, correlation was conducted using Beck Depression Inventory ( $\mathrm{r}=0.134)$. There was no significant association between family members' depression and hope. Cronbach's alpha for 0.932 and test-retest reliability coefficient was performed twice with an interval of 2 weeks. Therefore, correlation coefficient between the two phases was 0.54 . Since p value was 0.014 , less than alpha, null hypothesis was rejected $(\mathrm{p}<0.05)$. This showed a relationship between the two phases for 12 
family members which indicated a correlation between family members' hope before and after the test. To determine the amount of Cronbach's alpha for this scale, after checking face and content validity it consisted of 68 statements. Internal consistency was assessed using Cronbach's Alpha which was 0.594. After crossing out fifteen statements Cronbach's alpha value upgraded to 0.713. In the third stage, Cronbach's alpha reached to 0.874 after removing questions 5, 14 and 15 . Finally, the scale of the sample consisted of 126 family members of patients admitted to intensive care units which participated and all of the questions in the questionnaire were answered. Hence, Cronbach's alpha raised to 0.932 . Since the scale of family members' hope in patients were used for the first time in Iranian mothers, exploratory factor analysis was conducted to determine the agents included in the structure of the scale. Therefore, we used principal component factor analysis with varimax rotation. Before performing factor analysis, Kaiser-Mayer-Okin (KMO) statistic and Bartlett's test were used to assess the equality of variance. KMO and Bartlett's Test series showed that despite wide variation between the coefficients correlation, the matrix was suitable for factor analysis (16). Minimum load factor for the proposed statements were 0.3 ; therefore, in this study, the amount was considered as 0.3 . After entering data into SPSS version 18, they were analyzed using factor analysis, correlation, and Cronbach's alpha coefficients.

\section{Results}

In the present study, the three main components included Compatibility- hope, Self-esteem-peak of hope and Moving to the front- motivational hope (Table 1). The demographic characteristics of the patients' family members are listed in Table 2. In Table 3, to determine the factor, structure of the questionnaire showed hope in families of patients in Intensive Care Units (with a variance of 73.948\%) (Table 3). Questionnaire of hope for family members of patients hospitalized in intensive care units were divided into four subscales. After attribution of the statements among four agents, statements with the highest factor loading were placed under their appropriate agents. These agents were named according to the nature and size of the variables, and agents extracted from them had the maximum contribution, glossary of terms, implications of variables, existing theories, and previous studies (2). The first agent consisted of 7 items which represented 16.664 of the total variance. It was inserted under "compatibility", second agent with a value of 13.134 was "self-confidence". The third agent with a value of 12.571 was "Sense of responsibility". The fourth agent was "Looking to the future" with a value of 9.390 of the total variance. Cronbach's alpha coefficients obtained from analysis of questionnaires completed by family members of patients was 0.916 . Cronbach's alpha under the first scale (compatibility) was 0.898 , Cronbach's alpha of the second subscale (selfconfidence) was $87 \%$, Cronbach's alpha under the third subscale (Sense of responsibility) was 0.770 . The fourth subscale (Looking to the future) was 0.571. Pearson correlation coefficients between the scores obtained from two family members' responses to the hope scale were 0.939 , which showed that scale stability was average.

Table1. Hope from the perspective of family members of patients (qualitative part)

\begin{tabular}{|l|l|l|}
\hline $\begin{array}{l}\text { Some of the statements of patients' } \\
\text { families associated with hope }\end{array}$ & Sub-categories & Main category \\
\hline $\begin{array}{l}\text { I am compatible with these } \\
\text { circumstances; I'm going to take care of } \\
\text { the patient; I feel responsible }\end{array}$ & $\begin{array}{l}\text { Self-care, spirituality, faith, optimism } \\
\text { responsibility, family assistance and } \\
\text { better compatibility }\end{array}$ & $\begin{array}{l}\text { Compatibility-Hope suitability } \\
\text { Nurses help facilitate } \\
\text { communication and patients' } \\
\text { family members }\end{array}$ \\
\hline $\begin{array}{l}\text { Hope means the good care of my } \\
\text { patient for me; I feel my patient's } \\
\text { situation is good; I love him/her more } \\
\text { than ever; I am treating my patient with } \\
\text { the help of nurses. This gives me hope }\end{array}$ & $\begin{array}{l}\text { Responsibility, caring, Sense of joy, } \\
\text { openness and self-confidence, } \\
\text { increase knowledge and awareness, } \\
\text { instill hope, search for information, } \\
\text { caring, sense of fun and gaining hope }\end{array}$ & $\begin{array}{l}\text { Self-confidence, self-esteem, } \\
\text { sense of responsibility, self- } \\
\text { confidence. }\end{array}$ \\
\hline $\begin{array}{l}\text { I hope my patient will get better soon, } \\
\text { and we will go from here; I do not cry } \\
\text { in the presence my patient; I would like } \\
\text { my child to reach basic need, and I } \\
\text { want to be a good mother for my child }\end{array}$ & $\begin{array}{l}\text { A sense of joy and enthusiasm means } \\
\text { hope, technology, a source of } \\
\text { progress, looking to the future: fear } \\
\text { and hope, personnel support }\end{array}$ & $\begin{array}{l}\text { Moving to the front- } \\
\text { motivational hope }\end{array}$ \\
\hline
\end{tabular}


http://www.ephysician.ir

Table 2. Demographic characteristics of the patients' family members

\begin{tabular}{|l|l|l|l|l|}
\hline Row & Gender & Age (year) & Duration of hospitalization (days) & Relation with patients \\
\hline 1 & Male & 31 & 13 & Son \\
\hline 2 & Male & 61 & 8 & Brother \\
\hline 3 & Female & 34 & 12 & Sister \\
\hline 4 & Male & 40 & 11 & Brother \\
\hline 5 & Female & 32 & 20 & Daughter \\
\hline 6 & Male & 42 & 15 & Brother \\
\hline 7 & Female & 64 & 11 & Mother \\
\hline 8 & Male & 24 & 12 & Son \\
\hline 9 & Female & 26 & 13 & Daughter \\
\hline 10 & Male & 52 & 12 & Father \\
\hline 11 & Female & 37 & 17 & Sister \\
\hline 12 & Male & 45 & 15 & Brother \\
\hline
\end{tabular}

Table 3. Factor Analysis of Hope questionnaire in family members of patients

\begin{tabular}{|l|l|c|}
\hline no. & Statements & Agent \\
\hline 1 & I love to care for the sick & 0.932 \\
\hline 2 & I have a positive view on life & 0.932 \\
\hline 3 & I try to achieve my goals & 0.932 \\
\hline 4 & I look forward to meeting my patients & 0.931 \\
\hline 5 & I enjoy feeding the sick & 0.931 \\
\hline 6 & Through my previous experiences, I prepare for a better life & 0.710 \\
\hline 7 & I am happy that my patient is alive & 0.668 \\
\hline 8 & I always wanted to be involved in caring for the sick & 0.642 \\
\hline 9 & I will do everything for my patients' recovery & 0.625 \\
\hline 10 & I think that my patients are useful to society & 0.619 \\
\hline 11 & Hope is a profound feeling & 0.605 \\
\hline 12 & The hope of nurses is important to me & 0.599 \\
\hline 13 & I feel I have a great life & 0.587 \\
\hline 14 & I hope that my patient has a speedy recovery & 0.499 \\
\hline 15 & I am optimistic for the future & 0.441 \\
\hline 16 & I look at different aspects of the problem & 0.764 \\
\hline 17 & I will give positive energy to the sick & 0.762 \\
\hline 18 & I do not display sorrow at my patient's bedside & 0.622 \\
\hline 19 & Hope gives me the strength to care & 0.581 \\
\hline 20 & My love for my patient, is my hope & 0.554 \\
\hline 21 & I believe that I become calm & 0.550 \\
\hline 22 & I pray for healing the sick & 0.670 \\
\hline 23 & I am sure that the patient will recover & 0.636 \\
\hline 24 & Hope made me that with my sick & 0.573 \\
\hline 25 & I overcome my problems with hope & 0.541 \\
\hline 26 & When I look at my patients, I feel hope & 0.359 \\
\hline
\end{tabular}

\section{Discussion}

Our study showed that hope in the family members of patients in Intensive Care Units had features such as positive expectations, future-based goals, purposeful goals and realism, improving cognitive skills, mobility, safety and availability. For example, in our study inner strength and positive emotions of hope was our aim. It was shown that for having hope, these factors are required. In fact, these two factors can be part of hope. They could be created while caring for patients' family members. Bland and Darlington mentioned hope as the inner strength (3). In data obtained from interviews, participants spoke directly about positive feelings and inner strength. They assumed it as the result of the attitude of the patient's family and his previous experience. They raised these two factors as their motives for hope in patients and their family members. The result was more effort and better performance in the family. In the Campbell study, one participant stated that nurses can play an important role in creating hope in 
families of patients in the ICU, meaning that they were able to strengthen and support patients and create hope in their family (5). In the study of Clarke and Kissane, one participant mentioned that "I evaluated hope every day and I noticed that it can be changed every day". There is a fine line between hope and denial (6). In this study, the aspect of hope in terms of attitude and belief was raised. Another feature of hope in our study was the cognitive property and its availability. Family participation in care requires knowledge and awareness with the patient's family members. One of the factors in the hopes of patients and family members was having the necessary knowledge. The result provided better care and more effective participation of the patient and the nurses. Quality of care and continuity of care required the availability of the nurse. In this study, after analyzing the content featuring the concept of hope in the families, the title of 'participation in care' was agreed. Chien claimed that hope was not only a value, but was essential for having good health (7). Miller introduced hope as an action specific agent. People with hope may do things that may directly affect the desired result (9). In the present study, hope may involve trying to heal and comfort sick family members. Hsieh said in his research, however, hope for a future-oriented nature should be pragmatic. And if not, it may show a daydream or escape mechanism (12). In fact, the hope of life must be rooted in reality. In a study conducted by Dal Sook, it was found that hope in patients' family members on how to care for them affects the quality of life for the patient's family (14). Self-efficacy was another feature of hope in the present study. Self-efficacy refers to the beliefs or judgments of the sick family members and the ability to do their duties and responsibilities. The set of features such as satisfaction of care, being motivated, feeling useful, sense of spirituality, feeling of satisfaction and decrease in burnout which was obtained as analysis of interviews, were expressed with three subcategories of pleasant feeling, a sense of satisfaction and concern about the future. Graneheim referred to hope as a strategy for coping with stress, this may increase a person's ability to cope with stress. This strategy reduces the stress on the patient's family members, and can reduce the stress associated with hospitalization of the patient and family satisfaction (19). The results of this study showed that increasing awareness of the patient's family members can be effective in improving the quality of patient care by family. Feeling good, positive attitude and establishing a reasonable outcome expectancy (recovery, death with dignity and to gain experience) could be effective. Family members, with such an understanding of the concept of hope in the care of patients may provide the main task with comfort in the best possible way.

\section{Conclusions}

Hope scale of family members of patients admitted to intensive care" helps researchers to assess different aspects of hope in family members of patients admitted to intensive care. In examining the psychometric properties of "Hope scale of family members of patients admitted to intensive care", our study showed that validity and reliability of the scale was relatively high in all areas. Due to its simplicity of use and implementation, one can use it in other studies in which hope is a related variable and target groups are family members.

\section{Acknowledgments:}

The present study was approved by the Research Council of Iran University of Medical Sciences. Authors would like to thank and appreciate all those who assisted in this research.

\section{Conflict of Interest:}

There is no conflict of interest to be declared.

\section{Authors' contributions:}

All authors contributed to this project and article equally. All authors read and approved the final manuscript.

\section{References:}

1) Abrishamkar S, Jivad N. Epidemiological analysis of head trauma in patients admitted to Kashani hospital in Shahrekord. Shahrekord Univ Med Sci J. 2004; 4(5): 27-32.

2) Amendolia B. Hope and parents of the critically ill newborn: a concept analysis. Adv Neonatal Care. 2010; 10(3): 140-4. doi: 10.1097/ANC.0b013e3181dee83b. PMID: 20505424.

3) Bland R, Darlington Y. The Nature and Sources of Hope: Perspectives of Family Caregivers of People With Serious Mental Illness. Perspect Psychiatr Care. 2002; 38(2): 61-8. doi: 10.1111/j.17446163.2002.tb00658.x. PMID: 12132632.

4) Blanch D, Karkada S. Relationship between stress, coping and nursing support of patients admitted to intensive care units of Karnataka, India. Journal of Pediatric Nursing. 2009; 15(2): 152-8.

5) Campbell DT, Fiske DW. Convergent and discriminant validation by the multitrait-multimethod matrix. Psychol Bull. 1995; 56(2): 81-105. doi: 10.1037/h0046016. PMID: 13634291. 
6) Clarke DM, Kissane DW. Demoralization: its phenomenology and importance. Aust N Z J Psychiatry. 2002; (36): 733-42. doi: 10.1046/j.1440-1614.2002.01086.x. PMID: 12406115.

7) Chien WT, Chiu YL, Lam LW, Ip WY. Effects of a needs-based education programme for family carers with a relative in an intensive care unit: a quasi-experimental study. Int J Nurs Stud. 2006: 43(1): 39-50. doi: 10.1016/j.ijnurstu.2005.01.006. PMID: 16183062 .

8) Miller J, Powers MJ. Development of an instrument to measure hope. Journal of Nurs Res. 1998; $37: 6-9$.

9) Miller JF. Hope to healing: A Construct Central to Intensive Cares Nursing Nursing. Journal of Nursing care. $2007 ;$ 42(1): 12-9.

10) Herth K. Abbreviated instrument to measure hope: development and psychometric evaluation. J Adv Nurs. 1992; 17: 1251-9. doi: 10.1111/j.1365-2648.1992.tb01843.x. PMID: 1430629.

11) Snyder CR, Cheavans J, Michael ST. Coping, the psychology of what works. Journal of Oxford University. 1999: 205-31.

12) Hsieh HF, Shannon SE. Three Approaches to Qualitative content analysis. Qual Health Res. 2005; 15(9): 1277-88. doi: 10.1177/1049732305276687. PMID: 16204405.

13) Hinds PS, Gattuso JS. Measuring hopefulness in adolescents. Journal of Pediatric Oncology Nursing. 1998; 8(2): 92-4.

14) Kim DS, Kim HS, Schwartz-Barcott D, Zucker D. The nature of hope in hospitalized chronically ill patients. Int J Nurs Stud. 2006; 43: 547-56. doi: 10.1016/j.ijnurstu.2005.07.010. PMID: 16140301.

15) Morse JM. Approaches to Qualitative and Quantitative Methodological Triangulation. Journal of Nursing Research. 1995; 40(2): 120-3.

16) LoBiondo-Wood G, Haber J. Journal of Nursing Research. 6th Edition. USA, St Louis: Mosby Co; 2006; 33: 467-526.

17) Miller JF. Hope: a construct central to nursing. Journal of Nursing research. 2007; 42: 12-9.

18) Farran CJ, Herth KA. Hope and hopelessness. Journal of Critical clinical constructs. 1995; 11(3): 82-99.

19) Graneheim UH, Lundman B. Qualitative Content Analysis in nursing research: Concepts, procedures and measures to achieve trustworthiness. Nurse Educ Today. 2004; 24: 105-12. doi: 10.1016/j.nedt.2003.10.001. PMID: 14769454. 